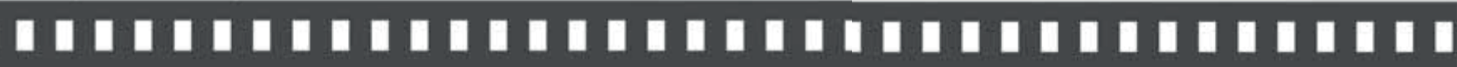

\section{Um corpo em estado de sombra: a construção do híbrido nas fotografias de Tiago Santana}

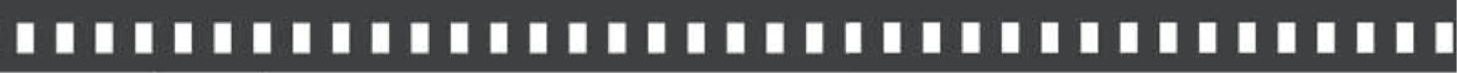

Tércia Montenegro Lemos

Artigo recebido em: 07/12/2017

Artigo aprovado em: 03/09/2018 


\title{
Um corpo em estado de sombra: a construção do híbrido nas fotografias de Tiago Santana
}

\author{
A body as a shadow: the creation of the hybrid in Tiago \\ Santana's photography
}

Tércia Montenegro Lemos*

\begin{abstract}
Resumo: A análise de imagens do fotógrafo cearense Tiago Santana demonstra como sua estética elabora uma composição híbrida dos corpos humano e animal. Suas figuras em simbiose ressaltam a interdependência dos seres no espaço sertanejo, através de diversas escolhas técnicas. Neste artigo, estudamos como a sombra é utilizada enquanto elemento ficcional e transformador da alteridade em identidade, instaurando, na obra de Santana, um paradoxo visual caracterizador da fotografia artística contemporânea.
\end{abstract}

Palavras-chave: Fotografia. Hibridismo. Corpo. Contemporaneidade.

Abstract: The analysis of images of the photographer Tiago Santana, from Ceará, demonstrates how his aesthetic elaborates a hybrid composition of human and animal bodies. His pictures in symbiosis, highlight the interdependence of beings in the Brazilian backwoods, through several technical choices. In this article, we study how the shadow is used as a fictional and causing element of the changing in identity, establishing, in Santana 's work, a visual paradox characteristic of the contemporary art photography.

Keywords: Photography. Hybridity. Body. Contemporaneity.

* Graduada em Letras pela Universidade Federal do Ceará, mestra em Letras e doutora em Linguística, também pela Universidade Federal do Ceará. É professora associada desta instituição, junto ao Departamento de Letras Vernáculas. 


\section{Introdução}

\section{A presença da sombra}

Eu acredito que o belo não é uma substância em si, mas é nada menos que um desenho de sombras, um jogo de claro-escuro produzido pela justaposição de substâncias diversas. ${ }^{1}$ Tanizaki $(2014$, p. 64)

Tradicionalmente a fotografia, já desde a sua etimologia, é associada à luz - o que, óbvio, não reduz tal linguagem artística a este único elemento composicional, inclusive porque, para a construção de um sentido, uma obra instaura sempre pluralidades que demarcam valores e estratégias utilizados. Falar de luz, consequentemente, é falar também de seu oposto: a ausência da luz, a escuridão, ou, conforme diversos níveis de intensidade luminosa, a sombra, a penumbra e demais variantes.

Victor Leronim Stoichita (2000, p.102) recorda que a sombra na pintura classicamente serviu como um sinal de volume, presença concreta, real. Por outro lado, a sombra é sempre deformante, apresenta-se como "o resultado de uma distorção". Devido a tal propriedade, a sombra popularmente passou a ser vista como a representação do alheio, do mistério - associado muitas vezes à alma, à consciência ou a energias espirituais. Rowley (2007) também nos lembra que se a luz desde a Antiguidade esteve associada à presença do divino, a sombra, num jogo de paralelismo, liga-se ao mal - ou, se não afirma o nefasto de maneira efetiva, ao 1 'Je crois que le beau n'est pas une substance en soi, mais rien qu'un dessin d'ombres, qu'un jeu de clair-obscur produit par la juxtaposition de substances diverses." 
menos sinaliza uma área desconhecida, que gera apreensão.

O clássico mito da caverna, de Platão, faz parte do nosso acúmulo de crenças em torno desse tema. Relacionando sombra a uma realidade ilusória, o filósofo grego compôs em sua alegoria uma ideia que intimamente associa luz a conhecimento, sabedoria, “a própria ideia do bem”. Em contrapartida, as projeções escuras na caverna seriam apenas "fantasmas" - ou seja, objetos que em si não têm consistência válida.

Para além disso, o corpo em estado de sombra é transformado, passa por um processo de ficcionalização, como ressalta ainda Stoichita (2000, p. 108): “A sombra [...] é, portanto, também a imagem de uma temporalidade ambivalente, de um tempo que se projeta na imagem para estabelecer a unidade entre ser e tornar-se, o que é possível com os instrumentos da ficção"2.

A fotografia de Tiago Santana vale-se desta estratégia ficcional para instaurar uma presença híbrida, que, no caso específico do corpus aqui analisado, indica a transformação da alteridade em identidade - ou seja, a sombra deixa de ser o território do outro para possibilitar a fusão de elementos distintos num corpo comum.

\section{Uma sombra projetada}

Eu sonhei em seguida com um cavalo do qual a cabeça era substituída por uma mão, mostrando com o polegar a direção adiante ${ }^{3}$. (2001, p. 112)

2 “L'ombre [...] est donc aussi l'image d'une temporalité ambivalente, d'un temps qui se projete dans l'image pour établir une unité entre être et devenir, ce qui est possible avec les instruments de la fiction."

3 "Je songeai ensuite à un cheval dont la tête était remplacée par une main montrant avec le petit doigt la direction en avant." 
A obra do fotógrafo cearense Tiago Santana privilegia paisagens sertanejas, ao mesmo tempo em que alcança cada vez mais uma difusão internacional, especialmente após a publicação da antologia intitulada Sertão (2011), que integra a prestigiosa coleção francesa Photo Poche, de livros de fotografia. Além deste título, Santana editou, pela Tempo D'Imagem, os volumes Benditos (2000), O chão de Graciliano (2006) e Céu de Luiz (2014), dentre outros.

Em sua estética, é confessa a influência de artistas como Miguel Rio Branco, com quem compartilha um determinado tipo de "modulação de esquemas corporais", no dizer de Bracchi (2014). Tal forma de organizar o discurso fotográfico não somente confirma a corrente da fotografia artística contemporânea que "valoriza o paradoxo, o duplo sentido, o jogo de figuras", mas resgata uma concepção de imagem que remete à fotografia surrealista, utilizando as colagens e "o jogo entre figuras para a construção de metáforas" (BRACCHI, 2014, p. 80).

Entretanto, a mediação plástica $a^{4}$ a metáfora visual criada por Rio Branco adquirem um outro nível de realização por Tiago Santana através da estratégia empregada pela fusão de sombras. Se Rio Banco estabelece um comparativismo através de dípticos em que as imagens, postas lado a lado, são levadas a um diálogo inevitável, Santana esboça um passo adiante rumo à integração física. As fotografias que aqui estudaremos não são apresentadas intencionalmente como um díptico, porém ainda assim veremos uma produtiva proximidade entre ambas.

$4 \quad$ Termo proposto pelo Groupe M (1992). 
Figura 1 - Sertão

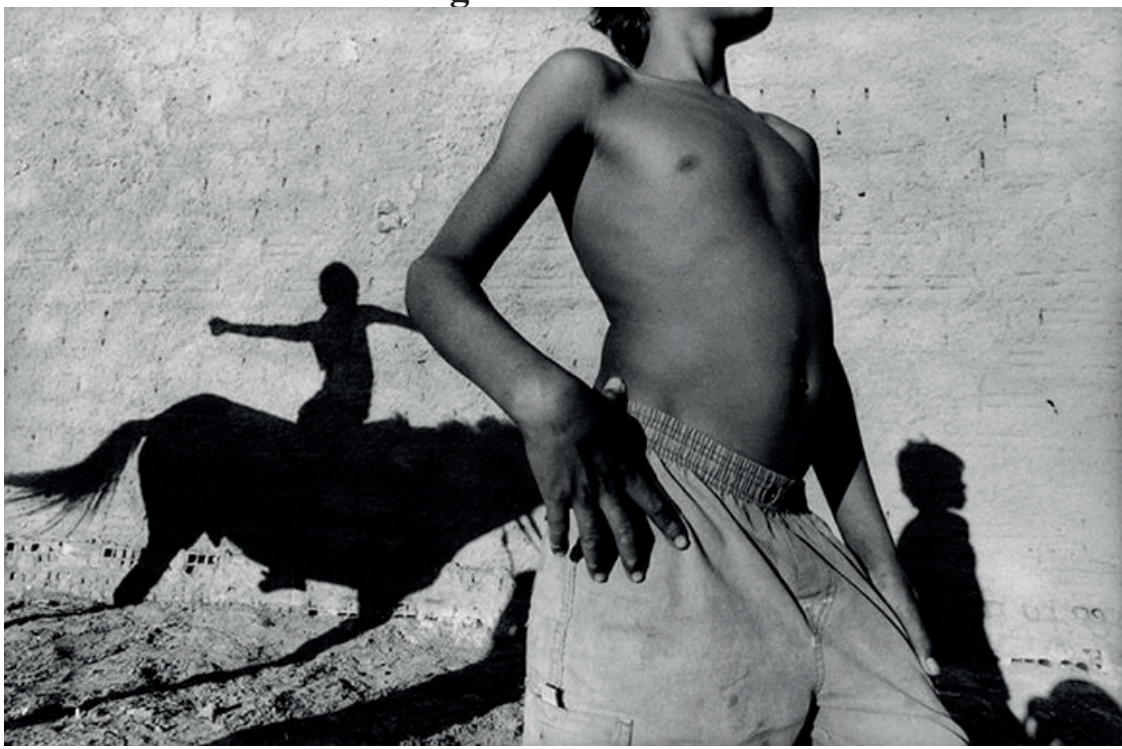

Fonte: Santana (2011, p. 70).

Figura 2 - Sertão

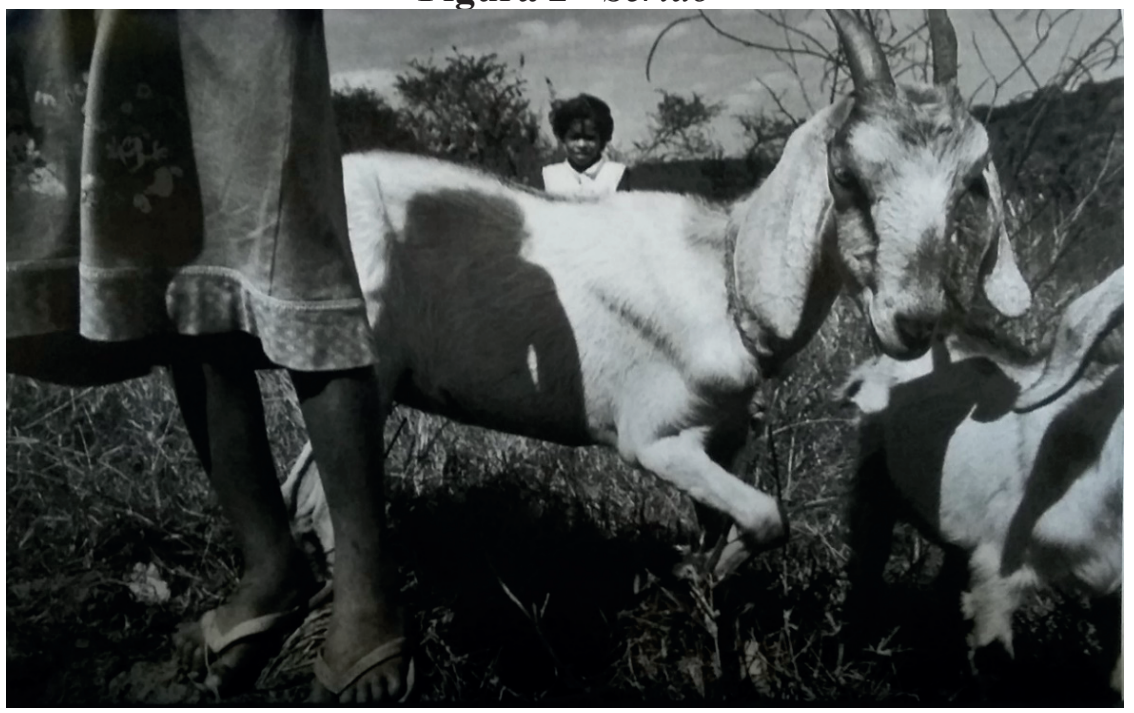

Fonte: Santana (2011, p. 67). 
A composição destas fotos mostra a formação de corpos que, se por um lado são mostrados em fragmentos, por outro lado têm suas partes dispostas em extrema consonância, aproximando elementos humanos e animais numa complementação figurativa. No primeiro caso, através da projeção da sombra de um cavalo sobre um muro, a silhueta não apenas nos mostra um interessante hibridismo entre cavaleiro e montaria (como se a criança que cavalga o bicho compusesse, com ele, um único ser, uma espécie de centauro ou criatura mítica), mas, para além disso, compõe, com o corpo do menino em primeiro plano, uma continuidade orgânica, na medida em que sua mão direita, aberta sobre o quadril, ocupa o lugar da cabeça do cavalo. A sugestão plástica inclusive é muito eficiente, com os dedos alongados sugerindo uma cara de perfil, e o polegar teso semelhando uma curta orelha.

Mas o mais interessante desta imagem fica por conta dos cortes fotográficos. $\mathrm{O}$ menino em primeiro plano surge decapitado pelo enquadramento, e os dois corpos infantis, projetados como sombras no muro, mantêm o anonimato justamente por serem apenas isso: sombras. A irreverência do garoto que cavalga o animal por brincadeira (não há indicação de movimento nas duas pernas projetadas, e uma outra sombra próxima, sinalizando talvez uma estaca, ou quem sabe mais um corpo humano, mostra que as rédeas estão presas) faz contraste com o menino ao centro, que parece posar, artificial e sério, enquanto sua silhueta se desenha no muro, acima da escura cabeça do fotógrafo. Esta surge à maneira de uma assinatura, no extremo canto direito da imagem.

A cena é válida inclusive se entendemos o posicionamento 
das figuras num sentido cronológico ${ }^{5}$, à maneira do que acontecia nas pinturas medievais, quando um único quadro trazia várias sequências de cenas a evoluir em narratividade da esquerda para a direita. Sob tal proposta, o ânimo lúdico evidenciado no primeiro garoto, descontraído e com os braços abertos, seria depois (numa fase subsequente da vida) substituído pela postura de seriedade do menino ao centro, que já parece encarar a responsabilidade do trabalho - e, nesse sentido, o fato de que sua mão (instrumento de tantos ofícios) esteja associada, como um prolongamento, à cabeça do cavalo, mostra como este animal é essencial para a labuta sertaneja. A presença do fotógrafo, que tem sua cabeça confundida, nas sombras, com o seu instrumento de trabalho - a câmera confirma a mensagem desta simbiose, além de, como já dissemos, remeter a uma ideia de marca autoral, assinatura de texto.

$\mathrm{Na}$ segunda foto, a projeção da sombra de uma garota sobre o dorso de um caprino cria um contorno grotesco, com a sugestão de selvageria confirmada pela textura dos pelos do animal, que parecem pertencer também a este corpo anômalo. Neste caso, a sombra não é densa o suficiente para nos dar uma sensação de pura escuridão: ativamos a nossa sensibilidade háptica à vista desses pelos que parecem preencher a silhueta, e então é como se estivéssemos diante de uma aparição temível, um tipo de ogro ou ser da linhagem do Pé-Grande ou do Yeti. Aqui podemos lembrar que esta construção do híbrido homem/animal já tinha sido apontada

5 Vale lembrar como um estudo clássico do Groupe $\mu$ (1987, p. 8) reflete sobre o fato de que, mesmo considerando a cronologia ausente numa sintaxe visual, visto que a sua disposição sintagmática funciona apenas espacialmente, "na nossa impossibilidade de conceber as coisas fora do tempo", não seria equivocado afirmar que um ícone já supõe um "poder de narração". 
por Eco (2007) como uma característica associada à feiura atroz, aspecto corroborado por Girard na seguinte passagem:

O monstro é o fim das diferenças sob forma monstruosa: partes de criaturas que normalmente deveriam ser diferenciadas de repente se encontram e se confundem, ou formam combinações as mais diversas, que geram objetos tais como centauros ou homens com cabeça de cavalo $^{6}$ (GIRARD, 1991, p. 98).

Em nossa análise, porém, observaremos que este "fim das diferenças", longe de gerar um simples caso de feiura ou de objetos monstruosos, produz uma intenção estética instauradora de verdadeiros sujeitos compósitos. Voltemos, por exemplo, à fotografia que estivemos comentando. Nela, contribui para a sensação de estranheza o surgimento da cabeça de uma outra garota em segundo plano, posicionada de tal maneira que parece nascida do dorso desta mesma cabra.

É de se notar como a brancura do vestido da menina quase se confunde com a pelagem do animal, e como seus ombros seguem a linha do horizonte - o que intensifica a sensação de leveza de sua presença. É uma cabeça que parece flutuar, tão instável quanto a sombra da outra garota parece ser pesada, praticamente brutal, nessa projeção compacta que atrai o nosso olhar tanto quanto o próprio olhar da cabra, voltado para nós. Somente um instante depois percebemos a presença de um outro animal, também caprino, e quase saindo de cena: seu corpo sofreu um corte no enquadramento

6 "Le monstre est la fin des différences sous forme monstrueuse: des parties de créatures qui normalement devraient être différenciées d'un coup se rencontrent et se confondent, ou forment des combinaisons les plus diverses, qui génèrent des objets tels les centaures ou les hommes à tête de cheval". 
do lado esquerdo da imagem e lhe falta a cabeça - da mesma forma como a garota em primeiro plano foi mutilada pela seção esquerda da foto. Mas, se desta figura humana podemos recuperar o corpo pela sugestão da sombra, o que poderia completar a dimensão física da segunda cabra? Ela possui todo o seu corpo, exceto... a cabeça! Justamente a única parte que emerge da menina ao fundo, que igualmente nos olha, como a primeira cabra...

\section{A sombra como impressão}

Se é possivel demonstrar que as sombras obedecem às leis elementares da ótica, elas não perdem por isso o seu lado inapreensível. Mesmo fazendo parte do nosso ambiente, elas aparecem e desaparecem, são fugidias e móveis [...] [as sombras] não pertencem ao mundo real. Não se pode tocá-las nem apreendê-las ${ }^{7}$. Gombrich (1996, p. 25)

"O caráter enganoso [...] constitui a fonte do prazer"": esta afirmação de Stoichita (1999, p. 36), voltada para a análise de naturezas mortas, também pode ser aplicada ao nosso estudo sobre a fotografia de Tiago Santana. A própria condição volátil, flutuante, da sombra, produz um conflito com a sua estabilização na obra fotográfica. E, além disso, lembremos, com Fontanille (2004),

7 "S'il est possible de démontrer que les ombres obéissent aux lois élémentaires de l'optique, elles n'em gardent pas moins leur côté insasissable. Tout en faisant partie integrante de notre environnement, elles apparaissent et disparaissent, elles sont fugitives et mouvantes [...]. [les ombres] n'appartiennent pas au monde réel. On ne peut les toucher ni les saisir."

8 "Le caractère trompeur [...] constitue la source du plaisir". 
que a sombra funciona enquanto impressão, marca ou vestígio levantando, novamente aqui, a sua ambiguidade: se é um sinal de presença, não é ainda presença completa. Ou, como diz este estudioso, a sombra é uma pista voltada para o enigma, para aquilo que vemos apenas por sugestão; a sombra é a "imagem que ainda não se fez".

O aspecto problemático da sombra é apontado também por Gagnebin (2002, p. 7); afinal, “quando há sombra, há problema para o espírito. Pensemos nas radiografias, na medicina, nas ecografias, mas também, na pintura, nos efeitos trompe l'œil ${ }^{9}$ '.

A sombra como anti-imagem, como o espelho cego ou o negativo do corpo são outras das associações levantadas em diversas pesquisas. Stoichita (2000) assinala - ainda a respeito dessa mística criada pelo elemento - que o quase desaparecimento da textura em áreas sombreadas contribui para a sua sensação de mistério: assim o "tocar com os olhos", a experiência háptica, encontra somente uma barreira, um vazio negro, e a sombra substitui a sinestesia da textura por uma zona de impenetrabilidade.

Nas fotografias de Tiago Santana, já notamos a tendência de instaurar uma atmosfera incógnita, com um repertório de figuras fabulosas criadas pelas sombras: não por acaso, vimos surgirem o centauro e o ogro, nas duas fotos em análise. Entretanto, o ponto principal das imagens não se detém aí. Pretendemos demonstrar que o estilo do fotógrafo, operando com base em fragmentações e cortes, bem como o seu tema, na defesa de uma integração física que atribui identidade aos corpos humano e animal, depende do uso da sombra.

9 “quand il y a ombre, il y a problème pour l'esprit. Pensons aux radiographies en medicine, aux échographies, mais aussi, en peinture, aux effets trompe l'œil”. 
A propósito de estilo, nunca é demais lembrar as palavras de Merleau-Ponty (2007, p. 113-114):

Há estilo (e com isso significação) tão logo haja figuras e fundos, uma norma e um desvio, um alto e um baixo, isto é, assim que certos elementos do mundo adquiram valor de dimensões pelas quais doravante medimos todo o resto, em relação às quais indicamos todo o resto. O estilo é, em cada pintor, o sistema de equivalências que ele monta para essa obra de manifestação, o índice geral e concreto da 'deformação coerente' pela qual ele concentra a significação ainda esparsa em sua percepção e a faz existir expressamente.

Assim, a "deformação coerente" instaurada por Santana demonstra um estreito vínculo com a presença das sombras. Comentamos anteriormente a deformidade no seu apelo mais imediato, ligado à distorção ou fusão das formas e capaz de criar, pela sombra, a figura de um centauro ou de um monstro, a partir, respectivamente, do corpo de um garoto sobre um cavalo e do corpo de uma menina. Agora, vamos nos dedicar à deformação introduzida pelos cortes de enquadramento - e perceberemos, no decorrer da análise, a coerência destas escolhas técnicas no diálogo com o tema das imagens.

\section{Uma imagem dentro da imagem}

As sombras são o meio pelo qual o corpo imprime sua forma na parede, funcionando como uma cicatriz no espaço. Bracchi (2014, p. 169) 
Nas imagens de Santana que escolhemos para análise, podemos observar que o corpo é percebido de duas maneiras: como invólucro e como superfície. No primeiro caso, ele aparece na forma de sombra, e nesse estado nem sempre é reconhecido em conformidade com o elemento físico do qual se projeta: é o que acontece quando vemos um monstro nascer da projeção de um corpo de menina. A sombra instaura uma silhueta ou moldura, e sua condição aqui é tão problemática quanto a de um quadro, conforme podemos depreender das palavras de Stoichita (1999, p. 36):

O quadro separa a imagem de tudo aquilo que é não-imagem. Ele define o enquadrado como mundo significante, diante do fora-de-quadro que é o mundo simplesmente vivido. Devemos, entretanto, nos questionar: a qual dos dois mundos o quadro pertence? A resposta é ambivalente: aos dois e a nenhum. O quadro não é ainda imagem e ele não é mais um objeto do espaço circundante. Ele pertence à existência, mas tem a sua razão de ser apenas na relação com a imagem. ${ }^{10}$

Nesta função encapsuladora, como invólucro de uma imagem, entretanto, pouco visível, a "moldura" instaurada pela sombra remete às características ambíguas atribuídas a este elemento.

Mas o corpo também pode ser tomado enquanto superfície; se o elemento físico está banhado em luz e é perfeitamente reconhecível, será usado como um suporte para a projeção da sombra. Assim, o

10 'Le cadre separe l'image de tout ce qui est non-image. Il définit l'encadré comme monde signifiant, face au hors-cadre qui est le monde simplement vécu. On doit cependant se demander: auquel des deux mondes le cadre appartient-il? La réponse ne peut être que bivalente: aux deux et à aucun. Le cadre n'est pas encore image et il n'est plus un objet de l'espace environnant. Il appartient à l'existence, mais ne reçoit sa raison d'être que par rapport à l'image." 
dorso da cabra funciona como uma parede, um muro. $\mathrm{O}$ animal leva em si a inscrição de uma aparência humanoide, da mesma maneira como o menino da primeira foto leva "atrás de si" (já que a sombra é o que está atrás da imagem) o corpo do centauro, ao qual confere uma cabeça.

O corpo enquanto superfície é nosso alvo de interesse agora, por indicar não somente um enquadramento, a criação de uma "imagem dentro da imagem", mas sobretudo a escolha técnica do fotógrafo e o seu método de decoupage figurativa. Pretendemos demonstrar que a sombra, na obra de Santana, é um método para marcar uma cesura, assim como outros tipos de corte que ele emprega em várias imagens. A sombra, em si, será um processo - e ao mesmo tempo um produto - desta decoupage.

É oportuno lembrar, com Dondero (2009, p. 33 - 34), que o traço de autenticidade da fotografia passa justamente por todas as decisões e práticas envolvidas no ato de enunciação fotográfica:

Da mesma maneira que a mão do pintor, através da gestualidade sensório-motora, autografa a tela, o gesto do disparador autentifica uma visão fotográfica, mesmo que o procedimento produtor apareça de uma vez, inteiramente mecânico. Em primeiro lugar, o olhar do fotógrafo e a tomada de posição corporal no espaço fenomenológico podem ser considerados como estratégias de autentificação de seu fazer sensório-motor; em segundo lugar, as técnicas e o número limite de tiragens de um mesmo negativo revelam escolhas autográficas. ${ }^{11}$

11 "De la même manière que la main du peintre, à travers la gestualité sensorimotrice, autographie la toile, le geste du déclencheur authentifie une vision photographique, bien que la procédure productive apparaisse d'emblée entièrement mécanique. En premier lieu, le regard du photographe et sa prise de position corporelle dans l'espace phénoménologique peuvent être 
Se, portanto, Tiago Santana autografa a sua obra, marca-a com seu estilo a partir de seu próprio posicionamento no momento da enunciação, do clique fotográfico, a escolha por um ponto de vista que dê relevância às sombras projetadas nos corpos é altamente intencional. E, se repararmos que existe uma alternância entre as figuras humanas e animais quanto ao papel de invólucro ou de superfície que seus corpos assumem, torna-se justo indicar uma falta de hierarquização entre estes seres. Ou seja, pessoas e bichos, igualmente, podem ser vistos banhados em luz ou apenas sugeridos em suas silhuetas. E, mais do que isso, as sombras contribuem para a criação de diálogo de complementaridade entre tais figuras, a partir dos cortes de enquadramento.

Já observamos que não é à toa que, numa das imagens, o menino em primeiro plano seja mostrado sem cabeça, bem como a sombra do centauro - que ganha uma cabeça somente pelo artifício de junção com a mão deste garoto. Da mesma forma, na outra imagem a menina de vestido florido é visível do pescoço para baixo: exatamente como a cabra menor, quase a sair de cena. A presença de uma outra cabeça humana, de uma segunda garota, parece preencher este lugar vazio - mas não é ocasional que ela seja vista quase a pairar sobre o dorso de um caprino. A fusão dos corpos, a sua interdependência - construída por jogos de luz, sombra e cortes fotográficos - deixa bem claro o tema destas obras: humanos e animais, no mundo sertanejo, têm uma relação equitativa.

considérés comme des stratégies d'authentification de son faire sensorimoteur; en deuxième lieu, les techniques et le nombre limité de tirages d'un même negatif relèvent de choix autographiques." 
Recordamos, com Agostineti e Santos (2011), que o sertão, enquanto espaço, é uma simbolização, uma construção subjetiva - e assim, por conseguinte, também o indivíduo sertanejo. Tiago Santana elabora perfis do sertão e dos seus habitantes a partir de escolhas de sentido, constructos teóricos que indicam uma preferência pela apresentação do espaço como propício à interdependência entre homem e animal, com destaque para uma reflexão sobre a existência e a relação das outras espécies com o ser humano, sem que este assuma uma posição de superioridade.

Ainda no território dessa discussão em torno de uma perspectiva social para a imagem, lembremos, com Dominique Baqué (1998, p. 225), o velho paradoxo da entrada da fotografia no mercado de arte, "efetuada a partir do menos nobre, de uma iconografia puramente documental". Se vemos resquícios dessa proposta na obra de Santana, por outro lado - seguindo o mesmo teórico - podemos observar como os jogos plásticos e críticos ganham em complexidade, nos exemplos que aqui trouxemos. Escapando da restrição de uma abordagem semiológica à la Barthes, que reduz a imagem ao referente, as fotografias de Santana articulam o documental à dimensão estética.

Também Michel Poivert (2016) ressalta como a fotografia foi responsável pela construção de uma imagem pensada como fato social - embora ela continue evocando os conceitos de imagem mental e psíquica, tal como Filosofia e Psicologia os entendem. Tal dubiedade é o que indica a dificuldade de pensar a fotografia contemporânea como sendo um objeto "ao mesmo tempo real e ficcional" , perpassado por uma "instabilidade entre expressão sujetiva e função documental, entre o experimental e o comum" 
(POIVERT, 2015, p. 186). Esse jogo dialético está, a nosso ver, bem explícito na obra de Santana.

\section{O tempo e a sombra}

Se no lugar de uma figura você coloca somente a sombra de um personagem, este é um ponto de partida original, do qual você previu a estranheza ${ }^{12}$. Gauguin (1954, p. 64)

Em nossas considerações finais, gostaríamos de destacar que na obra de Santana o trabalho com transparências, espelhos e outras superfícies que indicam texturas oscilantes ou "enigmáticas" desenvolve muitos aspectos que encontramos no uso do elemento sombra. A utilização de tais estratégias para construir mensagens com forte presença mística é uma tendência principalmente no caso de suas fotografias com tema religioso. Tomamos a decisão de indagar sobre o uso da sombra deslocado para um contexto em que se permite a invenção de corpos híbridos a partir deste recurso, justamente porque o nosso interesse era mostrar uma cena criada pela fusão física, pela projeção da sombra, de corpos humanos e animais. A síntese operada por esta montagem acabou por indicar uma interdependência reveladora do mecanismo social em que o sertanejo vive: o seu espaço doméstico, profissional e afetivo está perpassado pela presença de bichos, a tal ponto que a integração dos seres resulta muito mais natural que sua distinção ou separação hierárquica.

12 'Si au lieu d'une figure vous mettez l'ombre seulement d'un personnage, c'est un point de départ original, dont vous avez calculé l'étrangeté." 
Aqui haveria, portanto, uma presença híbrida instaurada, a transformação da alteridade em identidade - e tal resultado aponta uma hipótese interessante a ser testada em outro corpus, com outras figurativizações. A sombra pode ser aquilo que está fora do campo visual, mas que vem, ainda assim, integrar a imagem. Gombrich (2003, p. 11), inclusive, ressalta que o fato de a sombra ser uma imagem evocada, além de imagem mostrada, "mereceria uma análise com confrontações de uma larga base psicológica”. Esta ambiguidade, em si, já poderia gerar estudos produtivos.

Dentro de um apelo místico, porém, a noção de pressentimento, de simples sugestão do que ainda (ou já não) se fez presente em termos carnais engatilha a ideia de que nas fotografias de tema religioso a sombra teria também um valor essencial. Perceber como a luminosidade recai sobre imagens sacras, ou parece provir delas, motivaria um trabalho específico sobre esta parte da obra de Santana, à maneira do que fez Arrase em seus estudos sobre a Anunciação (1999) ou sobre a pintura de Vermeer (1993).

Como elemento volátil e fugidio, a sombra ainda levanta questões sobre o tempo. Por um lado, o tempo da enunciação fotográfica, o instante criador tão efêmero: um minuto depois, o jogo de corpos já se modificou, a luz é diferente, o equilíbrio sofreu novo arranjo. Por outro lado, o tempo da existência em si, igualmente passageiro, recorda que toda imagem fixada indica um efeito de anacronismo. E, no caso específico da sombra, o tempo sugerido por ela remete não somente a um passado, mas a qualquer coisa de mítica, de ancestral ou transcendente - sem deixar de compartilhar do momento da enunciação fotográfica. É nesta zona de negociação instável que Tiago Santana exerce sua comunicação artística. 


\section{Referências}

AGOSTINETI, Kaíque; SANTOS, Goiamérico Felício dos. Sertão: um olhar fotográfico. In: CONGRESSO DE CIÊNCIAS DA COMUNICAÇÃO NA REGIÃO CENTRO-OESTE, 13., 2011, Cuiabá, MT. Anais [...]. Cuiabá, MT: INTERCOM, 2011. Disponível em http://intercom.org.br/papers/regionais/ centrooeste2011/resumos/R27-0211-1.pdf. Acesso em: 12 abr. 2015.

ARRASE, Daniel. L'ambition de Vermeer. Paris: Adam Biro, 1993.

ARRASE, Daniel. L'Annonciation italienne: une histoire de perspective. Paris: Hazan, 1999.

BAQUÉ, Dominique. La Photographie plasticienne, un art paradoxal. Paris: Éditions du regard, 1998.

BRACCHI, Daniela Nery. Fotografia brasileira contemporânea a partir de Miguel Rio Branco. 2014. Tese (Doutorado em linguística) - Universidade de São Paulo, USP, São Paulo, 2014.

DONDERO, Maria Giulia. Le sacré dans l'image photographique: études sémiotiques. Paris: Lavoisier, 2009.

ECO, Umberto. História da feiura. Rio de Janeiro: Record, 2007.

FONTANILLE, Jacques. Soma et séma: figures du corps. Paris: Maisonneuve \& Larose, 2004.

GAUGUIN, Paul. Lettres de Paul Gauguin à Émile Bernard, 1881-1891. Genève: Pierre Cailler: Vésenaz, 1954. Disponível em: http://www.worldcat.org/title/lettres-de-paul-gauguin-a-emilebernard-1888-1891/oclc/7632420. Acesso em: 6 dez. 2015. 
GAGNEBIN, Murielle. L'ombre de l'image: de la falsification à l'infigurable. Paris: Éditions Champ Vallon, 2002.

GOMBRICH, Ernst Hans. Ombres portées: leur représentation dans l'art occidental. Paris: Gallimard, 1996.

GOMBRICH, Ernst Hans. Méditations sur un cheval de bois: et autres essais sur la théorie de l'art. Paris: Phaidon, 2003.

GIRARD, René. La violenza fondatrice. In: PETRA, Lorena. La narrazione dele origini. Rome: Giuseppe Laterza \& Figli, 1991. p. 98 .

GROUPE $\mu$. Illustrations pour une rhétorique. ART \& FACT, Liège, n. 6, 1987.

GROUPE $\mu$. Traité du signe visuel: pour une rhétorique de l'image. Paris: Le Seuil, 1992.

MAGRITTE, René. Écrits complets. Paris: Flammarion, 2001.

MERLEAU-PONTY, Maurice. A prosa do mundo. Tradução Paulo Neves. São Paulo: Cosac Naify, 2007.

PLATÃO. A república. São Paulo: Editora Escala Educacional, 2006. Livro VII.

POIVERT, Michel Poivert. Brève histoire de la photographie. Paris: Hazan, 2015.

POIVERT, Michel Poivert. La photographie est-elle une 'image'. Études photographiques, Paris, n. 34, p. 1-16, 2016.

RIO BRANCO, Miguel. Dulce sudor amargo. México: Fondo de Cultura Economica, 1985. 
112 Um corpo em estado de sombra: a construção do híbrido nas fotografias de Tiago Santana

ROWLEY, Neville. Daniel Arasse en perspective: une apostille à l'Annonciation italienne. Revista de História da Arte, Campinas, n. 6, 2007, p. 15-30.

SANTANA, Tiago. Sertão. Tours: Actes Sud, 2011.

STOICHITA, Victor Leronim. L'instauration du tableau. Genève: Librairie Droz, 1999.

STOICHITA, Victor Leronim. Brève histoire de l'ombre. Genève: Librairie Droz, 2000.

TANIZAKI, Jun'ichiro. Éloge de l'ombre. Préface et traduction du japonais par René Sieffert. Normandie: Verdier, 2014. 